\title{
Celdas de Combustible Microbianas (CCMs): Un Reto para la Remoción de Materia Orgánica y la Generación de Energía Eléctrica
}

\author{
Dolly M. Revelo(1), Nelson H. Hurtado ${ }^{(2)}$ y Jaime O. Ruiz ${ }^{(3)}$ \\ Universidad de Nariño, (1) Departamentos de Biología, (2) Departamentos de Química, (3) Departamentos \\ de Ingeniería Electrónica, Grupo de Investigación en Bioelectroquímica (BEQ),Calle 18 Carrera 50, \\ Campus Torobajo, San Juan de Pasto, Nariño-Colombia (e-mail: margo.revelo@gmail.com; \\ nhurtado@udenar.edu.co; jaimeruiz@udenar.edu.co)
}

Recibido Abr. 26, 2013; Aceptado May. 6, 2013; Versión final recibida Jun. 28, 2013

\begin{abstract}
Resumen
Se presentan y discuten los aspectos más importantes que inciden en el desempeño de una celda de combustible microbiana, tales como su arquitectura, la función microbiana y el tipo de sustratos. En la última década estos sistemas bioelectroquímicos han atraído el interés de diversos investigadores, no sólo por la tendencia mundial en la producción de energía sostenible, sino también por su operación simultánea para degradar materia orgánica y biorremediación. Estas aplicaciones dependen esencialmente del metabolismo microbiano sobre el cual el conocimiento aún es limitado, requiriéndose una mejor comprensión de la compleja ecología microbiana. En países en desarrollo es importante estudiar otras fuentes de microorganismos y sustratos con variada composición química que puedan ser potenciales combustibles en celdas de diferente configuración. Investigar más sobre estos aspectos será esencial para optimizar y potenciar estos procesos.
\end{abstract}

\section{Microbial Fuel Cells (MFCs): A Challenge for the Removal of Organic Matter and Electricity Generation}

\begin{abstract}
The most important issues that affect the performance of a microbial fuel cell, such as its architecture, microbial function and the type of substrates are presented and discussed. In the last decade these bioelectrochemical systems have attracted the interest of many researchers, not only because of the global trend towards sustainable energy production, but also due to their simultaneous operation to degrade organic matter and bioremediation. These applications depend essentially on microbial metabolism whose knowledge is still limited, being necessary a better understanding of the complex microbial ecology. In developing countries it is important to investigate others sources of microorganisms and substrates with varied chemical composition which might be potential fuels in cells of different configuration. More intense research of these aspects will be essential to optimize and improve these processes.
\end{abstract}

Keywords: microbial fuel cells, organic matter, biodegradation, bioremediation, electricity. 


\section{INTRODUCCIÓN}

Las Celdas de Combustible Microbianas (CCMs) son una tecnología emergente que podrían contribuir a solucionar dos de los problemas más críticos que afronta la sociedad actual: la crisis energética y la disponibilidad de agua no contaminada. Una CCM es un dispositivo que utiliza microorganismos para convertir la energía química presente en un sustrato en energía eléctrica, esto es posible cuando bajo ciertas condiciones algunos microorganismos transfieren los electrones producidos en su actividad metabólica a un electrodo (ánodo) en lugar de a un aceptor natural de electrones (como oxígeno). Este proceso contribuye a degradar la materia orgánica representada como sustrato o combustible (Pant et al., 2010) y ha sido estudiado ampliamente en CCMs de cátodo abiótico con la generación de energía eléctrica a pequeña escala (Du et al., 2007). La perspectiva de disponer de agua limpia para liberar al ambiente se fortalece al considerar las CCMs de biocátodo recientemente exploradas (Lovley, 2011), las que además de los beneficios ya mencionados, pueden contribuir a la biorremediación de compuestos tales como xenobióticos o metales pesados, debido a que los microorganismos pueden aceptar electrones desde el electrodo (cátodo) y reducir diferentes compuestos, volviéndolos ambientalmente más amigables.

Las CCMs se distinguen de otros sistemas de generación de energía porque: operan eficientemente a temperatura ambiente e incluso a muy bajas temperaturas; producen menor cantidad de $\mathrm{CO}_{2}$ que cualquier otra tecnología actual que utilice combustibles fósiles para generar energía, por lo que las pocas emisiones de este gas no requieren ningún tipo de tratamiento; no necesitan aporte de energía siempre que el cátodo abiótico sea aireado pasivamente o sea un biocátodo; en el futuro podrían ser utilizadas en lugares remotos donde haya demanda de consumos básicos de energía eléctrica. El potencial de estos dispositivos es enorme, en diversos trabajos se ha demostrado su efectividad (Rabaey et al., 2003, Du et al., 2007, Pant et al., 2010), lo que ha creado grandes expectativas en la comunidad científica ya que es posible producir energía limpia mediante la explotación de la biomasa que existe en las aguas residuales domésticas e industriales. Al utilizar la materia orgánica de las aguas residuales como combustible simultáneamente con la producción de energía, se consigue una depuración de las aguas contaminadas. Adicionalmente, el estudio de biocátodos capaces de usar no solamente oxígeno sino también otros contaminantes como posibles aceptores de electrones, permite la remoción de nutrientes y la biorremediación conjuntamente con la generación de electricidad (Huang et al., 2011).

Algunas importantes aplicaciones que se han descrito son el robot Eco Bot II que permite la realización de funciones de movimiento, sensado, computación y comunicación, este dispositivo tiene incorporado una CCM para obtener un sistema eléctricamente autónomo (Du et al., 2007); los biosensores para medir la Demanda Biológica de Oxígeno (Kim et al., 2003); el tratamiento de aguas residuales a pequeña escala para la eliminación de proteínas y otro tipo de compuestos químicos presentes en agua (He et al., 2013). Las posibles aplicaciones de CCMs de biocátodos están siendo recientemente exploradas (Huang et al., 2011), entre ellas sobresalen: biorremediación de $\mathrm{U}(\mathrm{VI})$ in situ, reducción de $\mathrm{Cr}(\mathrm{VI})$, eliminación de cloro de diversos solventes clorados, reducción de perclorato y principalmente reducción de nitrato. Por otra parte se explora la reducción de oxígeno y la producción de combustibles a través de la electrosíntesis microbiana en la cual se reduce el $\mathrm{CO}_{2}$ a compuestos orgánicos y la producción de hidrógeno (Lovley, 2011).

Son diversas las revisiones científicas disponibles sobre CCMs, cada una de estas con diferentes puntos de vista. Para citar algunas: Logan et al. (2006) presentan el diseño, la caracterización y el desempeño de las CCMs; Rabaey y Verstraete (2005) revisan la limitada información sobre el metabolismo energético y la naturaleza de las bacterias que usan el ánodo como aceptor de electrones; Chang et al. (2006) enfocan su discusión en el estudio de las bacterias electroquímicamente activas usadas en CCMs sin mediador que afectan el transporte de electrones. En Latinoamérica son escasas las publicaciones relacionadas con este tipo de dispositivos, en esta revisión se puntualizan en forma general los aspectos más relevantes de las CCMs con el propósito de entender las diferentes variables que afectan su operación.

En países desarrollados se sigue investigando en tecnologías como esta, potencialmente útil para procesos de remoción de materia orgánica, biorremediación y generación alternativa de energía. En entornos como el nuestro existe una gran diversidad de sustratos y microorganismos que podrían contribuir al desarrollo de CCMs, debido a que se han empleado diferentes sustratos como combustibles (Pant et al., 2010) y microorganismos que se encuentran en forma natural y abundante, tales como lodos anaeróbicos provenientes de aguas residuales, material de desecho de rellenos sanitarios, sedimentos de ríos o sedimentos marinos y muchas otras fuentes (Fuentes-Albarrán et al., 2012). Además, se pueden desarrollar CCMs a mayor escala profundizando sobre la arquitectura misma. El enfoque global de este tipo de dispositivos logrado en esta revisión científica es un producto de un trabajo multidisciplinario de áreas de microbiología, química e ingeniería electrónica, lo que permite adelantar investigaciones básicas y aplicadas de esta fascinante área de investigación. 


\section{ARQUITECTURA Y FUNCIONAMIENTO DE LAS CELDAS DE COMBUSTIBLE MICROBIANAS}

Una CCM típicamente está compuesta por dos cámaras (Fig. 1), una anaeróbica y otra aeróbica (Min et al., 2005) en medio de las cuales hay un separador. La cámara anaeróbica contiene sustratos orgánicos que al oxidarse por acción de los microorganismos, generan electrones, protones y $\mathrm{CO}_{2}$. En cada una de las cámaras se coloca un electrodo, el ánodo en la cámara anaeróbica y el cátodo en la cámara aeróbica (Du et al., 2007), una vez los electrones se liberan en la cámara anódica, éstos son captados por el ánodo y posteriormente transferidos hacia el cátodo mediante un circuito externo. Simultáneamente, en la cámara anódica se generan protones que migran hacia la cámara catódica a través del separador (Li et al., 2011), donde se combinan con el oxígeno del aire para reducirse a agua con los electrones que captan directamente del cátodo, debido a que esta reacción no está catalizada por microorganismos el cátodo se refiere como abiótico.

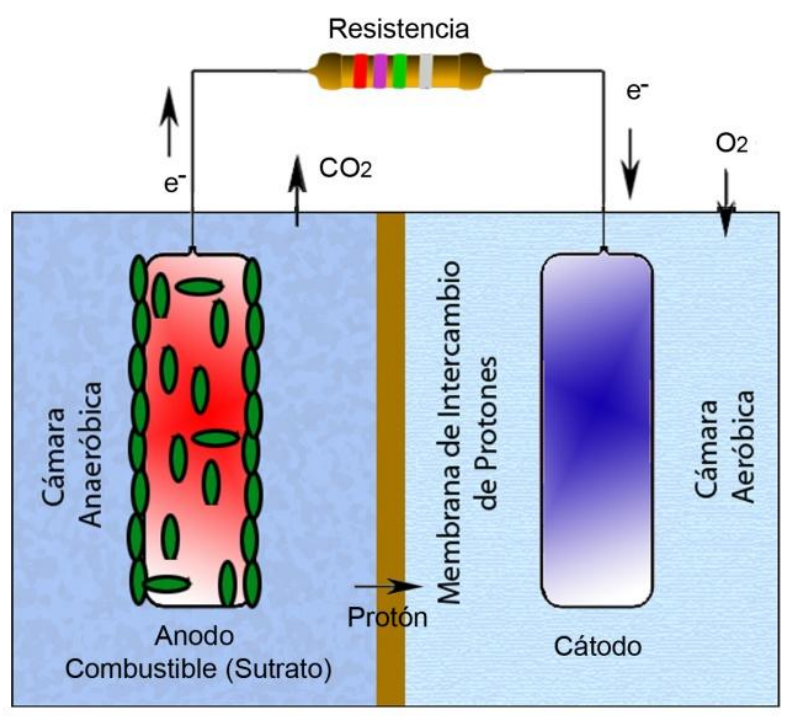

Fig. 1: Detalles principales de una CCM de cámara doble. Modificada a partir de Du et al. (2007).

La celda se fabrica en acrílico o en vidrio, para los electrodos se pueden utilizar diferentes materiales como cobre, platino, grafito u otros (Du et al., 2007). El separador, que es un importante componente del sistema porque es una membrana que impide el paso de electrones de la cámara anódica a la catódica y deja pasar los protones, puede ser de varios tipos: membrana de intercambio de cationes (MIC), membrana de intercambio de aniones, membrana bipolar, membrana de microfiltración, membrana de ultrafiltración, puente salino, fibra de vidrio, membranas porosas y otros materiales para filtrado (Li et al., 2011). El separador más ampliamente utilizado es la MIC que también se conoce como membrana de intercambio de protones (MIP) y entre ellas es muy común la Nafion, un producto de DuPont Inc., USA, que muestra una alta permeabilidad a los protones (Borole et al., 2009; Alzate-Gaviria et al., 2010; Wang et al., 2010).

Una variante de la CCM de doble cámara se obtiene eliminando la cámara catódica y exponiendo el cátodo directamente al aire, transformándose así en una CCM de una sola cámara; este hecho hace que sea un sistema mucho más sencillo y de menor costo (Du et al., 2007). No obstante, es conocido que las CCMs de una sola cámara pueden tener un separador, como las diseñadas por Park y Zeikus (2003) y Liu y Logan (2004) que utilizan una MIP o también pueden prescindir de éste, como las utilizadas por Yang et al. (2009) para estudiar su desempeño eléctrico.

En los últimos años se han desarrollado CCMs de biocátodo o de cátodo microbiano (Huang et al., 2011), en las que a diferencia de los cátodos abióticos los microorganismos son usados como biocatalizadores para aceptar electrones a partir del cátodo y así reemplazar el uso de catalizadores químicos costosos. Los biocátodos son de dos tipos: (1) biocátodos aeróbicos que usan oxígeno como el oxidante y microorganismos que asisten la oxidación de compuestos metálicos de transición, tales como $\mathrm{Mn}$ (II) o $\mathrm{Fe}$ (II), para la entrega de electrones al oxígeno; (2) biocátodos anaeróbicos que usan diferentes compuestos como aceptores terminales de electrones, tales como: nitrato, sulfato, $\mathrm{Mn}(\mathrm{IV}), \mathrm{Fe}(\mathrm{III})$, selenato, arsenato, fumarato, perclorato, cloroetenos, 2-clorofenol, $\mathrm{ClO}_{4}^{-}, \mathrm{U}(\mathrm{VI}), \mathrm{Cr}(\mathrm{VI}), \mathrm{H}^{+}, \mathrm{CO}_{2}$, entre otros (Sharma y Kundu, 2010; Huang et al., 2011). Estos biocátodos son de gran interés por su bajo costo, capacidad auto-regenerativa y sostenibilidad y además porque pueden contribuir a disminuir los altos potenciales catódicos. 


\section{Desempeño eléctrico de las CCMs}

El desempeño eléctrico de una CCM se estudia a partir de las mediciones de voltaje que se realizan en la resistencia externa conectada entre el ánodo y el cátodo y los respectivos cálculos que se derivan de ellas. Los parámetros que se analizan para evaluar el comportamiento eléctrico de este tipo de dispositivos son: la densidad de potencia (DP), la eficiencia coulómbica (EC) (Rismani-Yazdy et al., 2011) y la resistencia interna (RI) (Borole, et al., 2009).

La densidad de potencia (DP) expresada como la potencia por unidad de área del electrodo anódico (1) (Wang et al., 2010) o la potencia por unidad de volumen del sustrato (2), (Luo et al., 2010), se calcula de la siguiente manera:

$P_{A}=\frac{I U}{A}$
$P_{V}=\frac{I U}{V}$

Donde, I es la corriente en amperios, $U$ es el potencial en voltios, $A$ es el área de la superficie del electrodo anódico en $\mathrm{m}^{2} \mathrm{y} \vee$ es el volumen del sustrato de la cámara anódica.

Con relación a la resistencia interna $(\mathrm{RI})$ éste es un parámetro muy importante para caracterizar un generador de corriente como lo es una CCM. Se puede obtener a partir del análisis de las curvas de polarización que se derivan de las mediciones de voltaje en la resistencia externa (Hoyos et al., 2007; Rismani-Yazdy et al., 2011), o por la técnica de espectroscopia de impedancias (Hou et al., 2012; FuentesAlbarrán et al., 2012), que se fundamenta en la aplicación de una pequeña señal de voltaje a la celda electroquímica y posterior medición de la corriente a través de ella (Ramírez et al., 2009).

La eficiencia coulómbica $(E C)$ es un parámetro que permite obtener la fracción de energía eléctrica que se puede generar en la CCM a partir de un sustrato determinado. Su medición es importante porque posibilita comparar el desempeño de diferentes CCMs. La EC se calcula como la razón entre la carga generada y la carga teórica presente en el sustrato de la cámara anódica (Sharma y Li, 2010), mediante la siguiente expresión matemática (Luo et al., 2010):

$E C \%=\frac{i_{i=1} U_{i} t_{i}}{R F b \Delta S V} M \times 100$

Donde, $\mathrm{U}_{\mathrm{i}}$ es el voltaje de la CCM en el tiempo $\mathrm{t}_{\mathrm{i}}$, $\mathrm{R}$ es la resistencia externa, $\mathrm{F}$ es la constante de Faraday (96485 C/mol),b es el número de moles de electrones producidos por una mol de demanda química de oxígeno (DQO), $\Delta S$ es la concentración removida de $\mathrm{DQO}(\mathrm{g} / \mathrm{L}), \mathrm{V}$ es el volumen del líquido $(\mathrm{L})$ y $\mathrm{M}$ es el peso molecular del oxígeno $(32 \mathrm{~g} / \mathrm{mol})$.

En diversas publicaciones se observan claras diferencias en cuanto al desempeño eléctrico de las CCMs, debido a que son varios los factores que lo afectan, entre ellos: la arquitectura (Rismani-Yazdy et al., 2011), el tipo de separador utilizado (Sharma y Li, 2010), el material de los electrodos (Hou et al., 2012), el sustrato (Choi et al., 2003; Bond y Lovley, 2003; Chaudhuri et al., 2003) y los microorganismos (Rabaey y Verstraete, 2005).

En estas investigaciones, los autores describen algunas combinaciones específicas entre los diferentes factores que inciden en el desempeño eléctrico de una CCM, ellos analizan el comportamiento de una o dos variables, sin embargo, es muy complejo establecer una condición óptima que logre los mejores resultados. Las variables inciden de diferente forma: por ejemplo, la salinidad del sustrato mejora la conductividad y la resistencia interna del sistema, pero afecta el proceso metabólico de las células (Lefebvre et al., 2012). Los electrodos que mejor contribuyen al desempeño eléctrico por su alta habilidad catalítica son muy costosos (Hou et al., 2012). A pesar del uso de soluciones buffer en las cámaras de las CCMs, se pueden generar gradientes de $\mathrm{pH}$ que inciden en el desempeño eléctrico (Huang et al., 2011).

En términos generales en una CCM la producción de energía, a escala de laboratorio es muy baja, no obstante, en algunos trabajos se describen aplicaciones asociadas a sistemas electrónicos de bajo consumo (Du et al., 2007). En este orden de ideas, la perspectiva es experimentar con otras arquitecturas de celda y otros escenarios que involucren grandes volúmenes de materia orgánica (Fuentes-Albarrán et al., 2012), con lo que se esperaría mayores niveles de densidad de potencia. 


\section{TRANSFERENCIA EXTRACELULAR DE ELECTRONES}

\section{Transferencia de electrones desde el microorganismo al ánodo}

En un bioánodo existen bacterias electroquímicamente activas (Chang et al., 2006) que transfieren los electrones directamente al ánodo a través de proteínas de membrana como los citocromos tipo $c$, o de conductos proteicos denominados pili que sirven como nanoconductores; estudios genéticos han demostrado que la eficiente transferencia de electrones a través de una biopelícula de Geobacter sulfurreducens requiere de su presencia (Reguera et al., 2005, 2006; Holmes et al., 2006). Otras bacterias que no pueden hacerlo debido a la naturaleza no conductiva de su membrana celular, requieren de mediadores de electrones exógenos o endógenos (Du et al., 2007). Estos mediadores se reducen durante la oxidación metabólica de materiales orgánicos y su forma reducida es luego re-oxidada al transportar los electrones hacia el ánodo, el cual se mantiene a un alto potencial eléctrico (Chang et al., 2006), este proceso cíclico permite una mayor velocidad de transferencia de electrones incrementando la salida de energía (Du et al., 2007).

Los buenos mediadores deberían poseer las siguientes características (Du et al., 2007): atravesar la membrana celular fácilmente, tomar los electrones a partir de la cadena transportadora, poseer una alta velocidad de reacción con el electrodo, tener una buena solubilidad en el anolito, no biodegradables ni tóxicos para los microorganismos, de bajo costo y que tengan un potencial de reducción lo más cercano posible al del componente biológico para mantener una adecuada transferencia de electrones (Bullen et al., 2006). Es común usar mediadores exógenos sintéticos (tintes y metal orgánicos) tales como: rojo neutro, azul de metileno, tionina, azul de meldola, 2-hidroxi-1,4-naftoquinona, Fe(III) EDTA y otros compuestos hidrofílicos (Chang et al., 2006). Desafortunadamente, la inestabilidad de los mediadores sintéticos, su costo y su alta concentración, que llegaría a ser tóxica para el microorganismo, limita sus aplicaciones en las CCMs (Chang et al., 2006; Du et al., 2007); por lo tanto, las CCMs sin mediadores son ventajosas en el tratamiento de aguas residuales y la generación de energía porque se elimina principalmente el costo del mediador.

Cuando se utiliza una mezcla de microorganismos es común la presencia de mediadores endógenos, estos pueden ser metabolitos secundarios, como en el caso de Shewanella putrefaciens y Pseudomonas aeruginosa, o metabolitos primarios observados en Escherichia coli y en Sulfurospirillum deleyianum; los mediadores redox producidos por una bacteria pueden ser usados por otras para transferir los electrones al ánodo (Rabaey y Verstraete, 2005).

\section{Transferencia de electrones desde el cátodo al microorganismo}

Los mecanismos de transferencia de electrones en los biocátodos son similares a los del bioánodo, en este proceso los microorganismos pueden llevar a cabo reacciones de transferencia directa con participación importante de citocromos tipo $c$ e hidrogenasas, y reacciones de transferencia indirecta con mediadores redox naturales tales como PQQ (pirroloquinolinaquinona) (Rosenbaum et al., 2011); sin embargo, estos procesos bioquímicos solo se están estudiando en los últimos años.

Los microorganismos capaces de aceptar electrones directamente a partir de electrodos se han denominado coloquialmente electrodo-oxidantes (Rittmann, 2006) o más formalmente electrótrofos (Lovley, 2011); en este caso, los electrones que reciben del cátodo son transferidos selectivamente a aceptores finales con altos potenciales redox $\left(E^{9}\right)$ que captan del medio (Mook et al., 2013), tales como protones, $\mathrm{CO}_{2}$, nitrato, fumarato, $\mathrm{Cr}(\mathrm{VI}), \mathrm{U}(\mathrm{VI})$, solventes clorinados, entre otros (Lovley, 2011). El mecanismo mencionado anteriormente permite visualizar un amplio rango de aplicaciones principalmente en biorremediación, debido a que muchos de los aceptores finales en su estado reducido pueden ser más amigables para el ambiente, por ejemplo, la reducción del nitrato contribuye a la remoción de compuestos nitrogenados o la reducción del $\mathrm{Cr}$ (IV) proveniente de aguas residuales de la industria del cuero hasta su forma menos tóxica $\mathrm{Cr}$ (III) (Huang et al, 2011). Además, en el sistema de biocátodo se pueden producir biocombustibles $\left(\mathrm{H}_{2}\right.$, butanol, $\mathrm{CO}_{2}$ reducido, entre otros) u otros compuestos químicos de interés (Lovley, 2011).

\section{MICROORGANISMOS EN LAS CCMs}

\section{Microorganismos en la cámara anódica}

Rabaey y Verstraete (2005) presentan una detallada revisión sobre la generación de electricidad bacteriana en la cámara anódica y señalan que los principales factores que influyen en la generación de energía son las vías metabólicas que gobiernan el flujo de electrones y protones, la influencia del sustrato y el potencial del ánodo. A altos potenciales anódicos, las bacterias pueden usar la cadena respiratoria en un 
metabolismo oxidativo y transferir electrones al ánodo, sin embargo, si el potencial del ánodo disminuye los electrones probablemente se depositan sobre aceptores de electrones alternativos (sulfato, nitrato, entre otros) y en su ausencia, ocurrirá la fermentación.

Recientemente se ha demostrado en cultivos mixtos que los microorganismos fermentativos pueden tener poca o nula capacidad para transferir electrones al ánodo, sin embargo, su metabolismo contribuye a la generación de energía en la CCM (Richter et al., 2008) ya que aportan subproductos que pueden ser utilizados como sustratos por otras poblaciones microbianas, permitiendo el establecimiento de interacciones sintróficas. Kiely et al. (2011) discuten diversas publicaciones que caracterizan la comunidad microbiana de los sistemas bioelectroquímicos, al destacar procesos sintróficos específicos que capacitan a una biopelícula para la generación de corriente eléctrica a partir de un sustrato; la sintrofía consiste en que ciertos microorganismos hidrolizan y fermentan compuestos orgánicos complejos y otros utilizan los subproductos para la generación de corriente, estableciéndose una estructura jerárquica con microorganismos dominantes dependiendo del sustrato empleado.

Con base en lo anteriormente expuesto la formación de una biopelícula sobre el electrodo mejora la producción de energía (Watanabe, 2008), sin embargo, la microbiología de una biopelícula en la CCM y las implicaciones de la ecología microbiana sobre el funcionamiento del sistema han sido poco estudiados (Lovley, 2008; Bretschger et al., 2010), por lo tanto, conocer los procesos de colonización, invasión y sucesión de las poblaciones microbianas que producen electricidad permitirá explorar nuevos métodos para la producción de energía sustentable y renovable (Logan y Regan, 2006), una investigación en este aspecto es presentada por Read et al. (2010).

Como inóculo para las CCMs se pueden emplear cultivos de una especie microbiana o cultivos mixtos (consorcios). En el primer caso, existe la posibilidad de modificar genéticamente la especie microbiana e interpretar más fácilmente los estudios con respecto a genómica y proteómica (Lovley, 2008). Para la especie G. sulfurreducens se ha investigado sobre el mecanismo de la transferencia de electrones al ánodo y su capacidad de oxidar completamente un compuesto orgánico para así contribuir más efectivamente a la producción de energía (Lovley, 2008); por ejemplo, esta bacteria es dominante cuando se utiliza lactato, acetato, formato, glucosa, entre otros sustratos. Mientras que para especies del género Shewanella los genes involucrados en la vía propuesta para la transferencia extracelular de electrones son altamente conservados (Fitzgerald et al., 2013). Cabe resaltar que también se han empleado en la cámara anódica arqueas y la levadura Saccharomyces cerevisiae (Abrevaya et al., 2011; Rahimnejad et al., 2012).

A nivel práctico es mejor emplear cultivos mixtos porque estos generan altos potenciales y su manejo es más económico y menos exigente, por lo que se utilizan lodos anaeróbicos y otras fuentes de comunidades microbianas (Du et al., 2007). En los consorcios anódicos, las bacterias más comunes pertenecen a los géneros Shewanella, Geobacter, Proteobacter y Pseudomonas, se destacan las especies S. putrefaciens, $P$. aeruginosa, $G$. sulfurreducens y $G$. metallireducens. Diferentes estudios resaltan otras especies bacterianas que hacen transferencia directa o utilizan mediadores (Sharma y Kundu, 2010; Fernando et al., 2013).

En cuanto a aspectos puntuales sobre la electricidad generada por microorganismos, Debabov (2008) afirma que como resultado de los avances de los últimos 10 años, la densidad de potencia de las CCMs incrementó en diferentes órdenes de magnitud, de $0,1 \mathrm{~mW} / \mathrm{m}^{2}$ a $4,3 \mathrm{~W} / \mathrm{m}^{2}$. Du et al. (2007) discuten que los valores más altos se obtuvieron usando ferricianida en la cámara catódica, de esta manera las CCMs más eficientes no son operativas a escala comercial por la contaminación que podría ocasionar este mediador.

Algunos de los valores de densidad de potencia representativos publicados en la literatura se pueden observar en la Tabla 1, hasta ahora los máximos valores de densidad de potencia han sido producidos con cultivos mixtos o con la especie G. sulfureducens. Con el fin de aumentar estos valores otros investigadores han demostrado recientemente que se puede emplear la ingeniería metabólica para inhibir la síntesis de lactato, lo cual incrementó la liberación de electrones (Yong et al., 2012).

\section{Microorganismos en la cámara catódica}

Entre los microorganismos electrótrofos que pueden aceptar electrones de la superficie del cátodo de manera directa o mediada (Rittmann, 2006), sobresalen especies como G. sulfurreducens y S. putrefaciens, la mayoría de las bacterias en biocátodos son Gram-negativas, pero algunas Gram-positivas tales como Micrococcus luteus, Bacillus subtilis y Staphylococcus carnosus, también hacen una transferencia directa de electrones, otras como Acinetobacter calcoaceticus excreta compuestos activos redox para transferir electrones al oxígeno catódico y Dechlorospirillum anomalous WD acepta electrones del cátodo para reducir perclorato (Huang et al., 2011). 
Actualmente se está explorando la eficacia de microorganismos que actúan sobre el cátodo y aunque en algunos casos, estos microorganismos requieren fuentes de energía adicionales para mantener su actividad biocatalítica (Rosenbaum et al., 2011), aún son desconocidos los mecanismos por los cuáles las células conservan energía y crecen como electrótrofos. En este sentido Lovley (2011) discute sobre los aspectos conocidos hasta el momento cuando se emplean bacterias; sin embargo, también se han empleado microalgas (Mitra y Gordon, 2012) y ya se conoce un primer informe sobre la inoculación del hongo Coriolus versicolor en la cámara catódica que demostró que la producción de la enzima lacasa por el hongo mejoró la eficiencia de reducción de oxígeno a agua y esta CCM produjo más alta densidad de potencia que la CCM control (Wu et al., 2012).

Los microorganismos en las CCMs juegan un papel importante en la transferencia de electrones, un proceso que ocurre en la célula misma, de la célula hacia el electrodo y del electrodo a la célula; por lo tanto, estudiar sus interacciones, identificarlos y establecer su función en este proceso, aporta al conocimiento básico y al futuro mejoramiento del desempeño de estos sistemas. Además explorar consorcios eficaces para las funciones de generación de electricidad, remoción de materia orgánica y biorremediación, a partir de muestras ambientales sometidas a diferentes condiciones, puede permitir el desarrollo de novedosos bioánodos y/o biocátodos.

Tabla 1: Principales variables consideradas en CCMs generadoras de potenciales representativos.

\begin{tabular}{|l|l|l|l|c|c|c|l|}
\hline $\begin{array}{l}\text { Características } \\
\text { de la CCM }\end{array}$ & \multicolumn{1}{|c|}{ Bacterias } & Sustrato & Tipo de electrodo & $\begin{array}{c}\text { DP } \\
\left(\mathrm{mW} / \mathrm{m}^{2}\right)\end{array}$ & RI $(\Omega)$ & EC (\%) & Referencia \\
\hline $\begin{array}{l}\text { Cámara doble, } \\
\text { MIP Nafion 117 }\end{array}$ & $\begin{array}{l}\text { Lodo } \\
\text { anaeróbico }\end{array}$ & Acetato & $\begin{array}{l}\text { Papel carbón } \\
\text { (ánodo), platino } \\
\text { (cátodo) }\end{array}$ & 7200 & 960 & $50-80$ & $\begin{array}{l}\text { Oh et al. } \\
(2004)\end{array}$ \\
\hline $\begin{array}{l}\text { Cámara sencilla, } \\
\text { sin membrana }\end{array}$ & $\begin{array}{l}\text { Mezcla de } \\
\text { bacterias }\end{array}$ & $\begin{array}{l}\text { Acetato, } \\
\text { aguas } \\
\text { residuales }\end{array}$ & Fibra de carbono & 6860 & 235 & - & $\begin{array}{l}\text { Fan et al. } \\
(2008)\end{array}$ \\
\hline $\begin{array}{l}\text { Cámara doble, } \\
\text { MIP Ultrex }\end{array}$ & $\begin{array}{l}\text { Lodo } \\
\text { metanogénico, } \\
\text { anaerobio, } \\
\text { granular }\end{array}$ & Glucosa & $\begin{array}{l}\text { Varilla de grafito, } 5 \\
\text { mm de diámetro }\end{array}$ & 4310 & - & - & $\begin{array}{l}\text { Rabaey et } \\
\text { al. (2004) }\end{array}$ \\
\hline $\begin{array}{l}\text { Cámara doble, } \\
\text { MIC Nafion 117 }\end{array}$ & $\begin{array}{l}\text { Geobacter } \\
\text { sulfurreducens } \\
\text { KN400 }\end{array}$ & Acetato & $\begin{array}{l}\text { Varilla de 7.1x10 } 0^{-6} \mathrm{~m}^{2} \\
\text { (ánodo), tela de } \\
\text { grafito 6.4516 } \mathrm{cm}^{2} \\
\text { (cátodo) }\end{array}$ & 3900 & $\begin{array}{l}0.015 \\
\Omega / \mathrm{m}^{2}\end{array}$ & - & $\begin{array}{l}\text { Yi et al. } \\
(2009)\end{array}$ \\
\hline $\begin{array}{l}\text { Cámara sencilla, } \\
\text { MIP Nafion 115 }\end{array}$ & $\begin{array}{l}\text { Lodo de } \\
\text { digestor } \\
\text { anaeróbico }\end{array}$ & $\begin{array}{l}\text { Glucosa y } \\
\text { acetato }\end{array}$ & $\begin{array}{l}\text { Fieltro de carbono } \\
\text { suspendido en varilla } \\
\text { de grafito }\end{array}$ & 3650 & 27 & $88 \pm 5.7$ & $\begin{array}{l}\text { Borole et } \\
\text { al. (2009) }\end{array}$ \\
\hline $\begin{array}{l}\text { Cámara doble, } \\
\text { MIP Ultrex }\end{array}$ & Cultivo mixto & Glucosa & Grafito plano, $50 \mathrm{~cm}^{2}$ & 3600 & - & $89 \pm 4$ & $\begin{array}{l}\text { Rabaey et } \\
\text { al. (2003) }\end{array}$ \\
\hline
\end{tabular}

\section{SUSTRATOS}

El sustrato es uno de los aspectos más importantes de la CCM porque constituye el combustible a partir del cual se genera la energía. En la literatura científica se encuentran diversos trabajos en los que se emplea una gran variedad de sustratos, desde compuestos puros hasta mezclas complejas (Liu et al., 2009; Cha et al., 2010). En los primeros años, sustratos simples como glucosa y acetato eran de uso general, pero en los últimos años las investigaciones se centran en la utilización de sustratos menos convencionales con el fin de utilizar la biomasa presente en aguas residuales de diverso tipo y adicionalmente depurarlas y generar energía.

Los compuestos puros se pueden degradar de manera más simple lo que permite obtener mayor generación de energía e hidrógeno (Pant et al., 2010), además a nivel experimental es recomendable su uso porque se facilita la evaluación de condiciones operacionales de la CCM tales como, la eficiencia coulómbica, la densidad de potencia y la resistencia interna. Algunas investigaciones han empleado por ejemplo, acetato (Huang et al., 2010; leropoulos et al., 2010; Nam et al., 2010) debido a su inactividad hacia los procesos microbianos (fermentación y metanogénesis), glucosa (Li et al., 2010; Sharma y Li, 2010;), sacarosa (leropoulos et al., 2005), almidón (Shimoyama et al., 2008), lactato (Feng et al., 2010), ácido tereftálico (Song et al., 2009), tintes sintéticos (Ali, 2010), indol (Luo et al., 2010), lactosa, maltosa, xilosa, formiato, propionato, ácido succínico, etanol (Liu et al., 2010), entre otros. 
Sin embargo, el uso de sustratos complejos en una CCM es de gran interés porque, además de ser fuentes de energía, estos se pueden degradar y/o biorremediar antes de su descarga al medio ambiente. A diferencia de los compuestos puros los sustratos complejos requieren para su degradación una comunidad microbiana diversa y electroquímicamente activa (Pant et al., 2010), cuyas poblaciones se van seleccionando dependiendo del tipo de sustrato. Como ejemplos de este tipo de sustratos se pueden explorar: aguas residuales provenientes del procesamiento de frutas y vegetales, suero de queso, melazas de destilerías, aguas residuales de biorrefinerías, aguas residuales de industrias farmacéuticas con contaminantes recalcitrantes, residuos agrícolas, entre otros. Además, se ha demostrado que las CCMs pueden utilizar como sustratos no sólo material orgánico degradable, sino también material resistente a la biodegradación (Logan et al., 2006).

Son diversos los factores a tener en cuenta para seleccionar el sustrato a utilizar en la CCM, entre ellos el costo. Los sustratos puros resultan más costosos por las implicaciones de los procesos de obtención, en cambio, los sustratos complejos tales como los mencionados anteriormente son productos de desecho industrial o doméstico disponibles en forma abundante, de fácil consecución y por lo tanto económicos. Otro factor que normalmente incide sobre la generación de energía es la concentración del sustrato, esta dependencia es característica de las reacciones enzimáticas que ocurren en la CCM. Un incremento en la concentración del sustrato acelera la velocidad de reacción, lo que normalmente conduce a una mayor generación de energía; sin embargo, algunos autores han encontrado efectos contrarios y altas densidades de potencia a bajas concentraciones (Sharma y Li, 2010). Hay dos posibles razones que explican este comportamiento, primero, un incremento de los productos de fermentación que ocasionan una disminución del $\mathrm{pH}$ en el sistema, lo cual inhibe la actividad enzimática; segundo, algunos compuestos del sustrato orgánico son utilizados para el crecimiento bacteriano y no para la generación de electricidad (Sharma y Li, 2010).

La eficiencia de la CCM igualmente está afectada por sus condiciones de operación, entre ellas el pH electrolítico. Los gradientes de pH se producen por la acidificación en la cámara anódica y la alcalinización en la cámara catódica, esto se presenta debido a que en las reacciones anódicas se producen protones y en las reacciones del cátodo se consumen protones. Cuando en la cámara anódica la difusión y la migración de los protones a través de la MIP es lenta, se produce una disminución del pH ocasionando una disminución drástica de la actividad bacteriana y por consiguiente se afecta la transferencia de protones hacia la cámara catódica (Huang et al., 2011). De otro lado, el flujo de protones y de otros cationes alcalinos $\left(\mathrm{Na}^{+}, \mathrm{K}^{+}, \mathrm{NH}^{+}, \mathrm{Ca}_{2}{ }^{+}, \mathrm{y} \mathrm{Mg}_{2}{ }^{+}\right)$hacia el compartimiento catódico reduce el oxígeno y genera un incremento de $\mathrm{pH}$. La disponibilidad de protones en el cátodo es un factor clave que determina la eficiencia de reducción del oxígeno, así que, un aumento del pH en la cámara catódica puede disminuir significativamente la generación de corriente de la CCM. Termodinámicamente, un cambio en una unidad de $\mathrm{pH}$ causa en el electrodo una pérdida de potencial de $59 \mathrm{mV}$. Por lo tanto, para evitar los cambios de $\mathrm{pH}$ es necesario el uso de soluciones buffers de fosfato.

Una vez identificados los factores que inciden sobre el desempeño de una CCM se puede plantear el diseño de un sistema para una futura aplicación práctica. He et al. (2013) consiguieron descontaminar aguas de un lago en China, usando eficientemente una CCM como pre-tratamiento para su biorremediación. Se logró que la materia orgánica soluble disminuyera significativamente y simultáneamente se generó una densidad de potencia de $164 \mathrm{~mW} / \mathrm{m}^{3}$. Se encontró que el principal sustrato utilizado por la CCM fueron las proteínas presentes en las aguas del lago.

En este contexto, es de gran interés dedicar esfuerzos en investigación de este campo, ya que con frecuencia muchos de los métodos de purificación de agua no sólo se realizan químicamente, sino que también son energética y operacionalmente costosos. Hay una urgente necesidad de investigar un método más robusto, seguro y sostenible para descontaminar aguas residuales. Las CCMs ofrecen una excelente alternativa para el tratamiento de aguas residuales porque simultáneamente podrían utilizarse para descontaminar desechos industriales y generar energía eléctrica. Y aunque esta tecnología es emergente hay interesantes aplicaciones para estudiar a futuro tales como la bioelectrosíntesis y la reducción biocatalítica del $\mathrm{CO}_{2}$ (Schröder, 2011).

\section{CONCLUSIONES}

La revisión de la literatura, su análisis y la discusión realizada permiten obtener las siguientes conclusiones generales:

La CCM es una tecnología promisoria para propósitos de generación alternativa de energía, remoción de materia orgánica y biorremediación; sin embargo, para aplicaciones prácticas es necesario mejorar la 
eficiencia en los procesos bioelectroquímicos y en el desempeño eléctrico, por lo que se requiere investigar más en aspectos como diseño, comunidades microbianas, tipo y concentración de sustratos.

La posibilidad de utilizar diversos sustratos y comunidades microbianas hacen de las CCMs una tecnología factible de desarrollar en cualquier escenario porque estos componentes se encuentran en forma abundante y son de fácil acceso (suero de queso, aguas residuales provenientes de frutas y vegetales, melazas de destilerías, residuos agroindustriales, etc.). De esta forma, investigar el desempeño de una CCM utilizando diferentes combinaciones sustrato - comunidad microbiana permite obtener un sistema funcional y adaptable a las particularidades de cada región.

Desde la perspectiva de la investigación básica, la CCM constituye una oportunidad para profundizar en el conocimiento de las complejas interacciones entre una comunidad microbiana y un sustrato involucradas en los procesos de transferencia de electrones, aspecto que contribuye a la eliminación eficiente de los contaminantes de interés.

\section{AGRADECIMIENTOS}

Los autores agradecen el apoyo económico brindado por la Vicerrectoría de Investigaciones Postgrados y Relaciones Internacionales- VIPRI - UDENAR.

\section{REFERENCIAS}

Abrevaya, X.C., N. Sacco, P.J.D. Mauas y E. Cortón, Archaea-based microbial fuel cell operating at high ionic strength conditions, Extremophiles: 15(6), 633-642 (2011).

Ali, H., Biodegradation of Synthetic Dyes - A Review, Water Air and Soil Pollution: 213(1-4), 251-273 (2010).

Alzate-Gaviria, L., K. González, I. Peraza, O. García, J. Domínguez, J. Vázquez, M. Tzec- Sima y B. CantoCanché, Evaluación del desempeño e identificación de exoelectrógenos en dos tipos de celdas de combustible microbianas con diferente configuración en el ánodo, Interciencia: 35(1), 19-25 (2010).

Bond, D.R. y D.R. Lovley, Electricity production by Geobactersulfurreducens attached to electrodes, Applied and Environmental Microbiology: 69(3), 1548-1555 (2003).

Borole, A.P., C.Y. Hamilton, T. Vishnivetskaya, D. Leak y C. Andras, Improving power production in acetatefed microbial fuel cells via enrichment of exoelectrogenic organisms in flow-through systems, Biochemical Engineering Journal: 48(1), 71-80 (2009).

Bretschger, O., J.B. Osterstock, W.E. Pinchak, S. Ishii y K.E. Nelson, Microbial fuel cells and microbial ecology: applications in ruminant healt and production research, Microbial Ecology: 59(3), 415-427 (2010).

Bullen, R.A., T.C. Arnot, J.B. Lakeman y F.C. Walsh, Biofuel cells and their development, Biosensors and Bioelectronics: 21(11), 2015-2045 (2006).

Cha, J., S. Choi, H. Yu, H. Kim y C. Kim, Directly applicable microbial fuel cells in aeration tank for wastewater treatment, Bioelectrochemistry: 78(1), $72-79$ (2010).

Chaudhuri, S.K y D.R. Lovley, Electricity generation by direct oxidation of glucose in mediatorless microbial fuel cells, Nature Biotechnology: 21(10), 1229-1232 (2003).

Choi, Y., N. Kim, S. Kim y S. Jung, Dynamic behaviors of redox mediators within the hydrophobic layers as an important factor for effective microbial fuel cell operation, Bulletin Korean Chemical Society: 24(4), 437440 (2003).

Debabov, V.G., Electricity from Microorganisms, Microbiology: 77(2), 123-131 (2008).

Du, Z., H. Li y T. Gu, A state of the art review on microbial fuel cells: A promising technology for wastewater treatment and bioenergy, Biotechnology Advances: 25(5), 464-482 (2007).

Fan Y., E. Sharbrough y H. Liu, Quantification of the internal resistance distribution of microbial fuel cells, Environmental Science \&Technology: 42(21), 8101-8107 (2008). 
Feng C., F. Li, H. Liu, X. Lang y S. Fan, A dual-chamber microbial fuel cell with conductive film-modified anode and cathode and its application for the neutral electro-Fenton process, Electrochimica Acta: 55(6), 2048-2054 (2010).

Fernando, E., T. Keshavarz y G. Kyazze, Simultaneous co-metabolic decolourisation of azo dye mixtures and bio-electricity generation under thermophilic $\left(50^{\circ} \mathrm{C}\right)$ and saline conditions by an adapted anaerobic mixed culture in microbial fuel cells, Bioresource Technology: 127, 1-8 (2013).

Fitzgerald, L.A. y otros diez autores, Shewanella frigidimarina microbial fuel cells and the influence of divalent cations on current output, Biosensors and Bioelectronics: 40(1), 102-109 (2013).

Fuentes-Albarrán, C., A. Del Razo, K. Juarez y A. Alvarez-Gallegos, Influence of $\mathrm{NaCl}, \mathrm{Na}_{2} \mathrm{SO}_{4}$ and $\mathrm{O}_{2}$ on power generation from microbial fuel cells with non-catalyzed carbon electrodes and natural inocula, Solar Energy: 86(4), 1099-1107 (2012).

$\mathrm{He}, \mathrm{Y}-\mathrm{R}$ y otros nueve autores, Electricity generation from dissolved organic matter in polluted lake water usinga microbial fuel cell (MFC). Biochemical Engineering Journal: 71(No.), 57-61 (2013).

Holmes, D.E. y otros nueve autores, Microarray and genetic analysis of electron transfer to electrodes in Geobacter sulforreducens, Environmental Microbiology: 8(10), 1805-1815 (2006).

Hou, B., Y. Hu y J. Sun, Performance and microbial diversity of microbial fuel cells coupled with different cathode types during simultaneous azo dye decolorization and electricity generation, Bioresourse Technology: 111, 105-110 (2012).

Hoyos B.A., A.I. Restrepo y C.M. Mesa, Ánodos de Pt-Ru y Pt-Ir para celdas de combustible alimentadas con metano y propano directo, Información Tecnológica: 18(4), 41-46 (2007).

Huang L., J.M. Regan y X. Quan, Electron transfer mechanism, new applications, and performance of biocathode microbial fuel cells, Bioresource Technology: 102(1), 316-323 (2011).

Huang, Y., Zhen, H y F. Mansfeld, Performance of microbial fuel cells with and without Nafion solution as cathode binding agent, Bioelectrochemistry: 79 (2), 261-264 (2010).

Ieropoulos, I.A., J. Greenman, C. Melhuishy, J. Hart, Comparative study of three types of microbial fuel cell, Enzyme and Microbial Technology: 37(2), 238-245 (2005).

leropoulos, J., J. Greenman y C. Melhuish, Improved energy output levels from small-scale Microbial Fuel Cells, Bioelectrochemistry: 78(1), 44-50 (2010).

Kiely, P.D., J.M. Regan y B.E. Logan, The electric picnic: Synergistic requirements for exoelectrogenic microbial communities, Current Opinion in Biotechnology: 22(3), 378-385 (2011).

Kim, B.H., I.S. Chang, G.C. Gil, H.S. Park y H.J. Kim, Novel BOD (biological oxygen demand) sensor using mediator-less microbial fuel cell. Biotechnology Letter: 25 (7), 541-545 (2003).

Lefebvre, O., Z. Tan, S. Kharkwal y H. Y. Ng, Effect of increasing anodic $\mathrm{NaCl}$ concentration on microbial fuel cell performance, Bioresourse Technology: 112 (5), 336-340 (2012).

Li, J., G. Liu, R. Zhang, Y. Luo, C. Zhang y M. Li, Electricity generation by two types of microbial fuel cells using nitrobenzene as the anodic or cathodic reactants, BioresourceTechnology: 101(11), 4013-4020 (2010).

Li, W-W., G.P. Shen, X.W. Liu y H.Q. Yu, Recent advances in the separators for microbial fuel cells, Bioresource Technology: 102 (1), 244-252 (2011).

Liu, H. y B.E. Logan, Electricity generation using an aircathode single chamber microbial fuel cell in the presence and absence of a proton exchange membrane, Environmental Science Technology: 38(14), 40404046 (2004).

Liu, M. y otros cinco autores, Bioelectricity generation by a Gram-positive Corynebacterium sp.strain MFCO3 under alkaline condition in microbial fuel cells, Bioresource Technology: 101(6), 1807-1811 (2010). 
Liu, Z., J. Liu, S. Zhang y Z. Su, Study of operational performance and electrical response on mediator-less microbial fuel cells fed with carbon- and protein-rich substrates, Biochemical Engineering Journal: 45(3), 185-191 (2009).

Logan, B.E. y otros ocho autores, Microbial fuel cells: Methodology and technology, Environmental Science \& Technology: 40 (17), 5181-5192 (2006).

Logan, B.E. y J. M. Regan, Electricity-producing bacterial communities in microbial fuel cells, Trends in Microbiology: 14(12), 512-518 (2006).

Lovley, D.R., Powering microbes with electricity: direct electron transfer from electrodes to microbes, Environmental Microbiology Reports: 3(1), 27-35 (2011).

Lovley, D.R., The microbe electric: conversion of organic matter to electricity, Current Opinion in Biotechnology: 19(6), 564-571 (2008).

Luo, Y., R. Zhang, G. Liu, J. Li, M. Li y C. Zhang, Electricity generation from indole and microbial community analysis in the microbial fuel cell, Journal of Hazardous Materials: 176(1-3), 759-764 (2010).

Min, Booki., S. Cheng y B.E. Logan, Electricity generation using membrane and salt bridge microbial fuel cells, Water Research: 39(9), 1675 - 1686 (2005).

Mitra, P. y A.H. Gordon, Continuous microbial fuel cell using a photoautotrophic cathode and a fermentative anode, The Canadian Journal of Chemical Engineering: 90(4), 1006-1010 (2012).

Mook, W.T. y otros cinco autores, A review on the effect of bio-electrodes on denitrification and organic matter removal processes in bio-electrochemical systems, Journal of Industrial and Engineering Chemistry: 19(1), 1-13 (2013).

Nam, J.Y., H.W. Kim, K.H. Lim y H.S. Shin, Effects of organic loading rates on the continuous electricity generation from fermented wastewater using a single-chamber microbial fuel cell, Bioresource Technology: 101(1), S33-S37 (2010).

Oh, S., B. Min, B. E. Logan, Cathode performance as a factor in electricity generation in microbial fuel cells, Environmental Science Technology: 38(18), 4900-4904 (2004).

Pant, D., G. Van Bogaert, L. Diels y K. Vanbroekhoven, A review of the substrates used in microbial fuel cells (MFCs) for sustainable energy production, Bioresource Technology: 101(6), 1533-1543 (2010).

Park, D.H y J.G. Zeikus, Improved fuel cell and electrode designs for producing electricity from microbial degradation, Biotechnology and Bioengineering: 81(3), 348-355 (2003).

Rabaey, K., G. Lissens, S. Siciliano y W. Verstraete, A microbial fuel cell capable of converting glucose to electricity at high rate and efficiency, Biotechnology Letters: 25(3), 1531-1535 (2003).

Rabaey, K., N. Boon, S.D. Siciliano, M. Verhaege y W. Verstraete, Biofuel Cells Select for Microbial Consortia That Self-Mediated Electron Transfer, Applied and Environmental Microbiology: 70(9), 5373-5382 (2004).

Rabaey, K. y W. Verstraete, Microbial fuel cells: novel biotechnology for energy generation, Trends in Biotechnology: 23(6), 291-298 (2005).

Rahimnejad, M., A.A. Ghoreyshi, G.D. Najafpour, H. Younesi y M. Shakeri, A novel microbial fuel cell stack for continuous production of clean energy, International Journal of Hydrogen Energy: 37(7), 5992-6000 (2012).

Ramírez, N., A. Regueiro, O. Arias y R. Contreras, Espectroscopia de impedancia electroquímica, herramienta eficaz para el diagnóstico rápido microbiológico, Biotecnología Aplicada: 26(1), 65-71 (2009).

Read S.T., P. Dutta, P. L. Bond, J. Keller y K. Rabaey, Initial development and structure of biofilms on microbial fuel cell anodes, BCM Microbiology: 10(98), 1-10 (2010). 
Reguera, G. y otros cinco autores, Extracellular electron transfer via microbial nanowires, Nature: 435(7045), 1098-1101 (2005).

Reguera, G. y otros cinco autores, Biofilm and nanowire production leads to increases current in Geobacter sulfurreducens fuel cells, Applied Environmental Microbiology: 72(11), 7345-7348 (2006).

Richter, H. y otros cinco autores. Electricity generation by Geobacte rsulfurreducens attached to gold electrodes, Langmuir: 24(8), 4376-4379 (2008).

Rismani-Yazdy, H. y otros cinco autores, Effect of external resistance on bacterial diversity and metabolism in cellulose-fed microbial fuel cells, Bioresource Technology: 102(1), 278-283 (2011).

Rittmann, B.E., Microbial ecology to manage processes in environmental biotechnology, Trends in Biotechnology: 24(6), 261-266 (2006).

Rosenbaum, M., F. Aulenta, M. Villano y L. Angenent, Cathodes as electron donors for microbial metabolism: Which extracellular electron transfer mechanisms are involved?, Bioresource Technology: 102 (1), 224-233 (2011).

Schröder, U., Discover the possibilities: microbial bioelectrochemical systems and the revival of a 100-yearold discovery, Journal of Solid State Electrochemistry: 15(7-8), 1481-1486 (2011).

Sharma, V. y P.P. Kundu, Biocatalysts in microbial fuel cells, Enzyme and Microbial Technology: 47(5), 179188 (2010).

Sharma, Y. y B. Li, Optimizing energy harvest in wastewater treatment by combining anaerobic hydrogen producing biofermentor (HPB) and microbial fuel cell (MFC), International Journal of Hydrogen Energy: 35(8),3789-3797 (2010).

Shimoyama, T. y otros cinco autores, Electricity generation from model organic wastewater in a cassetteelectrode microbial fuel cell, Applied Microbiological Biotechnology: 80(2), 325-330 (2008).

Song, T., Y. Xu, Y. Ye, Y. Chen y S. Shen, Electricity generation from terephthalic acid using a microbial fuel cell, Journal of Chemical Technology and Biotechnology: 84(3), 356-360 (2009).

Wang, C., W. Chen y R. Huang, Influence of growth curve phase on electricity performance of microbial fuel cell by Escherichia coli, International Journal of Hydrogen Energy: 35(13), 7217-7223 (2010).

Watanabe, K., Recent Developments in Microbial Fuel Cell Technologies for Sustainable Bioenergy, Journal of Bioscience and Bioengineering: 106(6), 528-536 (2008).

Wu, C. y otros ocho autores, $A$ white-rot fungus is used as a biocathode to improve electricity production of a microbial fuel cell, Applied Energy: 98(10), 594-596 (2012).

Yang, S., B. Jia y H. Liu, Effects of the Pt loading side and cathode - biofilm on the performance of a membrane - less and single - chamber microbial fuel cell, Bioresource Technology: 100(3), 1197-1202 (2009).

$\mathrm{Yi}, \mathrm{H}$. y otros seis autores, Selection of a variant of Geobacter sulfurreducens with enhanced capacity for current production in microbial fuel cells, Biosensors and Biolectronics: 24(12), 3498-3503 (2009).

Yong, Y-C. y otros siete autores, Increasing intracellular releasable electrons dramatically enhances bioelectricity output in microbial fuel cells, Electrochemistry Communications: 19(3), 13-16 (2012). 